\title{
Critical factors that impact on the efficiency of the Lagos seaports
}

\author{
Authors: \\ Francis I. Ojadi ${ }^{1}$ \\ Jackie Walters ${ }^{2}$ \\ Affiliations: \\ ${ }^{1}$ Lagos Business School, \\ Lagos, Nigeria \\ ${ }^{2}$ Department of Transport \\ and Supply Chain \\ Management, University of \\ Johannesburg, South Africa

\section{Correspondence to:} \\ Frank Ojadi \\ Email: \\ fojadi@lbs.edu.ng

\section{Postal address:} \\ Department Operations \\ Management, Lagos \\ Business School, Pan-Atlantic \\ University (formerly Pan- \\ African University), Km 22 \\ Lekki-Epe Expressway, Ajah, \\ Lagos \\ Dates: \\ Received: 01 Apr. 2015 \\ Accepted: 13 May 2015 \\ Published: 29 July 2015 \\ How to cite this article: \\ Ojadi, F.I. \& Walters, J., 2015, \\ 'Critical factors that impact \\ on the efficiency of the \\ Lagos seaports', Journal of \\ Transport and Supply Chain \\ Management 9(1), Art. \#180, \\ 13 pages. $h t t p: / / d x . d o i$. \\ org/10.4102/jtscm.v9i1.180
}

\section{Copyright:}

(C) 2015. The Authors.

Licensee: AOSIS

OpenJournals. This work is licensed under the Creative Commons Attribution License.

Read online:
Background: Since the past two decades, the Lagos seaports have experienced vessel and storage yard cargo congestion, resulting in dwell times of about 30 days for containerised imports and high trade logistics costs.

Objectives: The purpose of this study was to identify the critical factors that impact the operational efficiency of the Lagos seaports with a view to improving liner trade activities.

Method: The study adopted an operational-based approach to understand the dynamics of the various interfaces of the port value chain. The research paradigm adopted for the study was therefore a combination of constructivism and post-positivism paradigms, which entailed the exploration and understanding of the various stakeholders in the port value chain. The epistemology of the research relied on the use of the exploratory sequential mixed method research technique (i.e. the qualitative approach followed by the quantitative approach) at the operational level of port operations.

Results: The result of the research showed that significant challenges exist and that some of these challenges cut across all functions of port operations. Challenges are experienced in the areas of corruption, trade fraud, transport infrastructure deficits, the absence of a supply chain culture and shortcomings in the execution of the 'contract of customs'. Additionally, these factors include the deficiencies in services and facilities provided by state agencies and government-appointed service providers and private sector companies such as truckers, inland container depots, Inland Container Depots (ICDs) and terminal operators.

Conclusion: Specific recommendations are made to address the issues identified which, if implemented, could significantly address the current inefficiencies observed in the Lagos seaport's operations.

\section{Introduction}

Seaports play important roles in the development of trade as they serve as gateways and transit points through which imports and exports flow into and out of a country. As such, seaports are critical elements of global supply chains. Global trade enhances economic development, and many countries have taken advantage of this linkage by reducing or eliminating obstacles that slow down the movement of cargo through their seaports. Slow moving cargo often results in high dwell times that lower seaport efficiency, and negatively impacts on the cost of trade and the competitiveness of a country.

Economic progress through global trade has been slow for many developing countries particularly in Sub-Sahara Africa (SSA) (Dean \& Sebastia-Barriel 2004:310-320). The slow rate of trade growth could be attributed to the high cost of trade which appears to be driven by (amongst other factors) the inadequacies in transport infrastructure and regulatory issues (Economic Report on Africa 2004). Over the past two decades, whilst efforts have concentrated on improving port efficiency through the provision of seaport infrastructure, and the adoption of relatively modern port management models, such as the involvement of private sector port operators and customs reforms, relatively little effort has been exerted to understand the root causes of port inefficiency at the operational level, particularly in Sub-Saharan African countries. For instance, Table 1 shows that in the particular case of the Lagos seaports ${ }^{1}$ (concessioned to private port operators in 2006 with significant investments from the concessioners [Bureau of Public Enterprises \{BPE\} 2006, 2008]), only minimal improvements have been achieved regarding the 'time to import and

\footnotetext{
1.The Lagos seaports were the sites of the fieldwork. The Lagos seaports are made up of two major ports: Apapa port and the Tin Can Island port. The Apapa port includes the Apapa container terminal (APMT) concessioned to A.P. Moeller, whilst the Tin Can Island port Island port. The Apapa port includes the Apapa container terminal (APMT) concessioned to A.P. Moeller, whilst the Tin Can Island port
is made up of the Tin Can Island container terminal (TCIT), Ports and Cargo Handling Services Ltd. (PCHS) and the Five Star Logistics Ltd. The TCIT handles only containers, whilst PCHS handles $70 \%$ of containerised cargo and $30 \%$ of general cargo. The Five Star Logistics Ltd. is a RORO terminal but has acquired a mobile shore crane for container handling in the last quarter of 2012. The focus of this study is on the container terminals (APMT, TICT and PCHS) as they handle over $80 \%$ of the container traffic at the Lagos seaports.
} 
TABLE 1: Nigeria's international ranking in trading across borders.

\begin{tabular}{|c|c|c|c|c|c|}
\hline Year & Rank (trade across border) & Time to export (days) & Time to import (days) & Cost to export (USD per TEU) & Cost to import (USD per TEU) \\
\hline 2008 & 138 out of 178 & 26 & 46 & 1026 & 1047 \\
\hline 2009 & 138 out of 181 & 25 & 42 & 1179 & 1306 \\
\hline 2010 & 146 out of 183 & 25 & 41 & 1263 & 1440 \\
\hline 2011 & 146 out of 183 & 24 & 39 & 1263 & 1440 \\
\hline 2012 & 149 out of 183 & 24 & 39 & 1263 & 1440 \\
\hline 2013 & 154 out of 185 & 24 & 39 & 1380 & 1540 \\
\hline
\end{tabular}

Source: World Bank and IFC co-publication (2008, 2009, 2010, 2011, 2012, 2013)

TEU, Twenty-Foot Equivalent Unit.

time to export' between 2008 and 2013 (World Bank [WB] 2008-2013). This illustration suggests that the search for the root cause or causes of port inefficiency lies somewhere else, perhaps within the dynamics of the operational flow of cargo through the port, other than the inadequacies in transport infrastructure (Alderton 2008). Based on Hummels (2001) and Djankov, Freund and Pham's (2006) estimates of the benefits of the swift flow of cargo through the ports, it is important to identify and address the factors that impact on port efficiency.

Port efficiency studies of Sub-Saharan Africa and other African seaports have been approached from different perspectives by different researchers (Barros 2012; Barros, Assaf \& Ibiwoye 2010; Barros \& Peypoch 2012; Eniola et al. 2014). Raballand et al. (2012) and Refas and Cantens (2011) are amongst the relatively few studies that have an economic perspective which empirically demonstrate that the high dwell time of cargo, which negatively impacts on port efficiency, could be the result of factors other than transport infrastructure inadequacies, as has been previously held. Indeed, other port researchers have discussed port efficiency of non-Sub-Saharan Africa ports from different perspectives, including the use of physical and financial indicators such as:

- vessel turnaround time and income (Trugillo \& Nombella 1999)

- the Data Envelopment Analysis (DEA) approach (Park \& Prabir De 2004)

- the logistics and supply chain approach (Bichou \& Gray 2005)

- the use of non-parametric efficiency estimators (Simoes \& Marques 2010).

The Government of Nigeria had in the past adopted different strategies to ensure the swift flow of cargo through its seaports, but these had resulted in marginal logistical improvements, as depicted in Table 1. The strategies include the Nigerian seaports modernisation project which involved:

- the World Bank (Bureau of Public Enterprises [BPE] 2006; WB 2002)

- the establishment of inland container depots within the vicinity of the Lagos seaports (LSN 2006)

- the switch from pre-shipment to destination inspection of imports

- the introduction of an electronic simplified customs clearance system (CBN 2002; Nigeria Customs Service [NCS] 2010).
TABLE 2: Time release study, Lagos Apapa Port.

\begin{tabular}{lcc}
\hline Clearing stages & Mean times (hours) & Standard deviation (hours) \\
\hline Face Vet & 22.86 & 33.94 \\
Data Input & 21.00 & 46.98 \\
Verification & 11.17 & 39.88 \\
Scan & 48.84 & 90.17 \\
Physical Examination & 29.20 & 60.36 \\
\hline Source: Nigeria Customs Services - Time Release Study, Jan. - Mar. (2007:13-35)
\end{tabular}

The NCS also conducted a Time Release Study to determine the cycle times for the different stages of clearing under the destination inspection scheme (NCS 2007). The result of the study, shown in Table 2, suggests a marked deviation from the mean times of the sequential clearing tasks, which indicates that customs clearance procedures took well over sixteen or more days during which time the cargo remained at the port of discharge.

The persistence of these challenges accentuates the need for a more detailed study into the factors that impact on the efficiency of Lagos seaports.

\section{Research objectives}

The primary objective of this research is to identify the critical factors that impact on the efficiency of the Lagos seaports.

The research questions are the following:

- What challenges affect the efficient flow of containerised goods through the Lagos seaports?

- What are the behavioural practices of the stakeholders involved in international trade through the Lagos seaports?

To be able to gain an insight into the challenges and difficulties associated with achieving the swift flow of goods through the Lagos seaports, this study also relied on the contextual underpinnings of the Nigerian government trade procedures and guidelines. The study also utilised the value chain construct to unpack the port operations in order to identify the interfaces and understand the meaning that the various port stakeholders make of the system as the cargo flows through the port.

\section{Literature review}

As the World Trade Organisation (WTO) negotiations, to reduce trade tariffs, continue to yield results, emphasis is now shifting to the reduction of non-tariff barriers that slow 
down the flow of cargo across the borders (WTO 2009). The drive to reduce non-tariff barriers and speed up the flow of cargo across countries is partly enhanced by the growth in trade volumes resulting from the increasing containerisation of goods such as agricultural products, security in trade operations, and partly by the desire to improve national competitiveness (Grainger 2011). Furthermore, the impetus to speed up the flow of cargo across the ports derives from the perceived estimated benefits from such activities (see Djankov et al. 2006; Hummels 2001).

The designers of several frameworks, designed to tackle the slow flow of cargo through the ports, have approached the issues from different perspectives. One such framework is the compilation of data on trading across borders for many countries by the 'Doing Business' group of The World Bank, which ranks countries according to the ease with which trade flows across their borders (see International Finance corporation/WB 2008, 2009, 2010, 2011, 2012, 2013 for results for Nigerian ports). Another framework is the Time Release Study of the World Customs Organisation (WCO) that focuses on the time taken between the arrival of cargo at the ports and their release from customs to the shipper (WCO 2011) (see NCS 2007 for the results for Nigerian port).

The study of the slow flow of cargo through ports has attracted the attention of several authors. From a trade perspective, Staples (2002:139-148) calls it the 'plumbing of international trade'. Grainger $(2007,2011)$ developed a conceptual review of trade facilitation aimed at opening up the issues for more academic discussions and identified the stakeholders in the trade value chain. The author developed a category of regulatory components and related activities, the majority of which are executed at the ports, in order to encourage a better understanding of the issues at stake (Grainger 2011). The categories include revenue collection, safety and security, the environment and health, consumer protection and trade policy. The activities related to the revenue collection category include the collection of customs duties and other indirect taxes, payment of duties and fees, and the management of bonds and other financial securities. Safety and security involves security and anti- smuggling controls, dangerous goods, vehicle checks, immigration and visa formalities and export controls. The United Nations Centre for Trade Facilitation and Electronic Business (UN/ CEFACT 2002 in Grainger 2011:41) defined trade facilitation as the 'simplification, and harmonisation of procedures and associated information flows required to move goods from the seller to buyer and to make payment'. This definition suggests the theoretical inclusion of the seller, the buyer, and all the other commercial (e.g. payment) and regulatory activities performed by government agencies and private sector operators at the ports, as the cargo flows from the seller across the ports to the buyer.

In so far as African ports are concerned, Refas and Cantens (2011) empirically analysed the reasons why cargo spends weeks in some African ports, whilst Raballand et al. (2012) studied the cargo dwell time at some SSA ports from an economic perspective. From the discussions on the frameworks and the research findings on improving port efficiencies, many issues are yet to be fully addressed. The 'Doing Business' group of The World Bank have explored the 'time to import and export' and identified the impact of bureaucratic red tape and inadequate transport infrastructure, amongst other factors, as impediments to the swift flow of cargo across the ports. However, in the opinion of the researchers, the 'Doing Business' group have not explored, in detail, the operational interfaces as the cargo moves from the seller to the buyer.

The WCO (2011) Time Release Study approach appears to limit the search to the factors that slow down the flow of cargo through the ports to customs related issues, rather than the other port value chain activities of which the customs clearance process is a component. The Refas and Cantens (2011) and Raballand et al. (2012) study approaches were based on economic modelling and the analysis of accumulated data from the Automated Systems for Customs Data (ASYCUDA) and Grainger (2011) advocates the evaluation and assessment of the operational variables.

From the foregoing it does appear that there is not yet any port efficiency study that has fully adopted an operational approach to understand the interfaces linking the port value chain role players with the meanings the various stakeholders attach to the interactions, as the cargo flows through the ports. This is certainly not as far as the Lagos seaports are concerned. An operational approach will, however, help identify the critical factors that cause delays at the ports, which impact on port efficiency and aid the formulation of solutions for improving the flow of cargo through the ports. The operational approach adopted in this research enhanced the exploration of the port operational interfaces. These elements will now be briefly discussed in the context of the research undertaken.

\section{The global trade value chain and the five contracts of trade}

Clark (2003) identifies over 40 different actors (business and government agencies) involved in the execution of commercial, transport, regulatory and financial steps in international trade. Grainger (2007) also outlines the different physical and regulatory activities required for the flow of goods across national borders.

Figure 1 depicts the global trade value chain with the seller and the buyer in different countries separated by a series of activities, which reflect the application of the global trade contracts. Whilst the physical activities in the exporting country involve production, local transportation and ocean or air shipment, some of the regulatory activities at the exporting country include the export declarations to customs authorities, transportation and insurance documentations, and financial arrangements with banking organisations. 


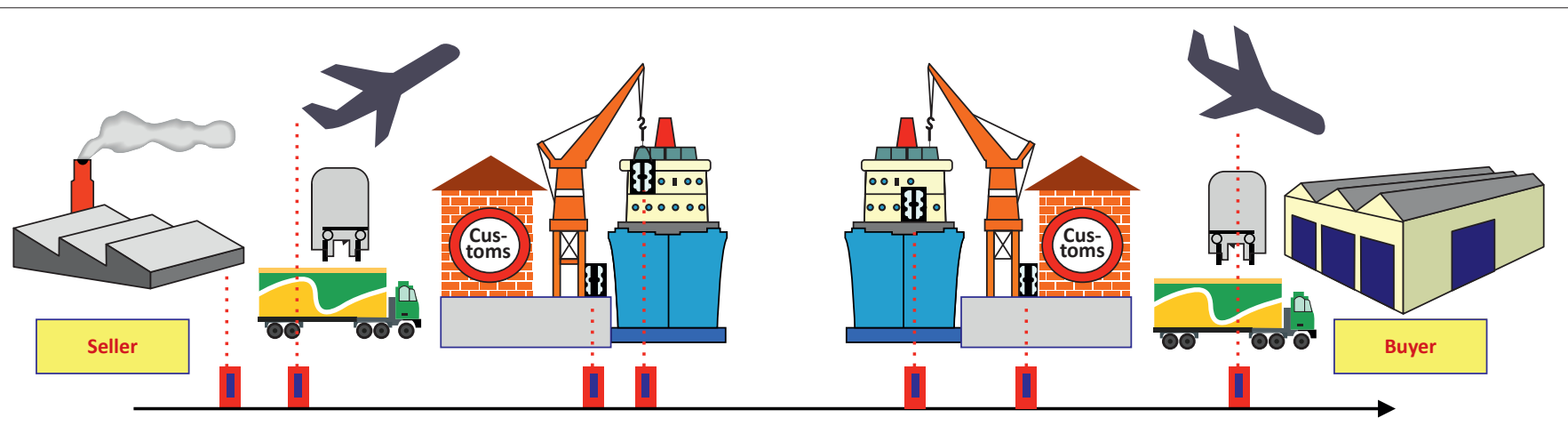

Source: International Trade Centre, 2000, Modular learning system on international Logistics, ITC Publication, Geneva, Switzerland, p. 235 FIGURE 1: Global trade value chain.

Similar but varying degrees of physical and regulatory activities must also be executed for the receipt of the imports at the border (air, sea or land) by the importing country. In the case of sea shipment, the physical and regulatory activities include vessel arrival and berthing, import declarations and clearance at customs, and transportation to the importing firm. In most countries other government agencies are involved at the border, with the customs as the lead agency. These include:

- immigration

- plant, drug and food inspectors

- police and security agencies

- trading standards organisations

- safety agencies (Grainger 2007).

Thus, the different physical and commercial activities comprise the five basic contracts that govern international trade flow from the seller to the buyer. These have been re-arranged accordingly:

- The contract for sale of goods (United Nations 2010).

- The contract of payment through documentary credits International Trade Centre (ITC 2000).

- The contact of carriage - bill of lading (ITC 2000).

- The contract of insurance (David \& Stewart 2010; ITC 2000).

- The contract of customs - completion of export and import formalities (David \& Stewart 2010; ITC 2000).

\section{The contract for sale of goods}

The diverse nature of international contracts involving business practitioners in different countries suggests that they are subject to greater risks than national contracts where the same country-specific legal requirements apply. In order to protect the interest of the principal partners, there is the need to have a common ground on which the sales contract is based. The UN (2010) details some basic and common clauses for structuring the sales contract.

The international terms of trade (Incoterms) are a set of three-letter standard contractual trade terms developed by the International Chamber of Commerce (ICC 2010), and are used in international contracts for the sale of goods (David \& Stewart 2010). Incoterms specify the key obligations of sellers, buyers and carriers with regard to delivery of the goods and the transfer of risks and costs (ICC 2010).

\section{The contract of payment}

The contract of payment forms part of the contract of sale where the seller and buyer must agree on the method of payment. There are different forms of payment, such as: open account, bills for collection, advance payments, and documentary letters of credit, with different levels of risks to the buyer and seller. Despite this, the ICC (2010) guidelines on uniform customs and practice for documentary credits prescribe the set of rules that govern the use of letters of credit - the most frequently used method of payment for imports and exports.

\section{The contract of carriage}

The contract of carriage is linked to the contract for sale of goods, but subordinate to it. The contract of carriage of goods is between the shipper (seller or buyer) and the carrier of the goods. The contract of carriage includes the handling of goods and the associated services over the stages of the journey between the premises of the seller and the buyer, and the private businesses and government agencies associated with port services and regulatory obligations.

\section{The contract of insurance}

Ordinarily, cargo insurance protects goods from a wide range of potential hazards as they transit between the seller and buyer premises. The terms of the sales contract specify the beginning and termination of risk for the principal parties whilst in transit, and the Incoterms tends to highlight who is directly responsible for the components of the risks as the goods flow from the seller to the buyer.

\section{The contract of customs}

Customs formalities are the various methods open to shippers to clear goods through customs. The declarations by the shippers require information and documentation 
necessary to enable the determination and application of all the duties and taxes, as specified in the fiscal policy of the nation.

The effective execution of the five contracts, in consonance with the local operating guidelines and procedures for imports and exports, provides the coordinating bedrock on which cargo flows from the seller to the buyer. The physical activities in the sequence are crucial, as any imperfection in the execution of any one of them may impede the flow of goods, and could lead to inefficiencies at the many cargo transfer points. For instance, whereas a seaport or container terminal may be very efficient in terms of the operational activities of unloading and stacking imported goods, the inability of a shipper to provide the necessary regulatory documentations required for the clearing of the goods could lead to the container being held up by customs, and may result in a build-up of containers at the terminal yard and, therefore, impact on the efficiency of the port. The trade contracts also provide the basis for an in-depth understanding of the operations of the government agencies at the interfaces, as cargo could hardly flow smoothly through a seaport or terminal with overlapping regulatory activities at cross purposes to each other.

\section{The value chain concept and seaport operations}

The activities that make up the seaport operations are closely interrelated and interdependent and must, therefore, be carefully coordinated if the port is to operate efficiently and effectively within the context of the international trade contracts. These activities describe the logistical chain of operations for handling containers and include the sea-side and the land-side of the seaport with the quay as the dividing front between them. Any activity that runs out of step with the others, resulting from internal or external factors, will inevitably disrupt and delay the smooth flow of containers. Thus, port logistical operations planning and control have attracted attention from operators and academics, the result of which is the publication of many container terminal optimisation studies within the maritime sector (Bichou 2009; Steenken, Voß \& Stahlbock 2004).

The value chain concept was, therefore, applied to the study as a basis for unpacking the activities and identifying the interfaces at the Lagos seaports, within the context of the five contracts of trade and the government trade guidelines and procedures. In a broad sense, the value chain concept looks at the activities undertaken by different actors and stakeholders in processes designed to transform various raw materials into finished products for sale. In a very narrow sense, the value chain also includes the series of activities that take place within a firm in order to produce a product. In both cases, the value chain construct is process-oriented and includes all the backward and forward linkages involved in the true conversion processes, as well as the issues of organisational coordination, and the power relationship of the various actors in the chain (Gereffi 1994; Kaplinsky \& Morris 2001; Porter 1985). Whilst the value chain construct has been used predominantly for manufacturing, it was applied to the Lagos seaports to identify the linkages between the various functions at the ports.

\section{Research method and design}

Research designs reflect research philosophical assumptions, plans and processes, including detailed methods of data collection and analysis:

Driving the entire process are the research problems being addressed, the specific world view assumptions brought to bear on the research, the strategies of inquiry and the unique methods of data collection, analysis and interpretation. (Creswell 2009:3)

Whilst there are different research methodologies used in supply chain management studies, of particular relevance to this study is the mixed method research strategy, which is predicated on a research approach requiring the integration and balancing of the qualitative and quantitative techniques in data collection and analysis (Kotzab, Seuring \& Reiner, 2005). The qualitative path of such an integration focuses on the first-hand learning of what the actors make of the dynamic or complex nature of the phenomenon under investigation, with little or no identified variables. The learning invariably relies on the philosophical assumption that knowledge is in the meaning people make of it (Creswell 1998 in Kotzab et al. 2005). On the other hand, the quantitative path relies on the outcome of the qualitative analysis to develop survey instruments to verify the substantive theories and issues derived from the qualitative path.

The identification of the actors (stakeholders) enabled the application of the sequential exploratory mixed methods research design to determine the challenges and deficiencies in the import and export flow of cargo through the seaports.

\section{Qualitative research path}

The qualitative research path of the mixed methods research strategy requires interviewing a purposive sample of each of the stakeholder groupings to obtain their views on the challenges that could impact on the efficiency of the Lagos seaports. The selection criteria for the sample of private organisations were based on years of experience, and the volume of imports and exports processed, handled and transported. Eight private stakeholder groupings ${ }^{2}$ were interviewed. Nine government agencies and governmentappointed private organisations were also interviewed ${ }^{3}$ (see Appendix 1).

The interviews were transcribed and analysed by utilising a plurality of approaches including coding, categorisation and

2.Truckers, importers, exporters, shipping lines, terminal operators, Inland container depot operators, banks, and customs brokers.

3.Central Bank of Nigeria (CBN), Standard Organisation of Nigeria (SON), Cotecna, Nigerian Maritime and Safety Agency, National Agency for Food, Drug Administration and Control (NAFDAC), Bureau of Public Enterprises (BPE), Nigeria Customs Service (NCS), Nigeria Ports Authority (NPA), Cobalt International Services Limited (CISL). 
themes. The reliability controls included the use of multiple interview transcribers and bouncing back the themes and categories to interviewees for reconfirmation.

\section{Quantitative research path}

The quantitative path comprised the formulation of the survey instruments, the pilot testing of the instruments, and the administration of the questionnaires on the representative sample of the stakeholders. A representative sample size ${ }^{4}$, of the organisations surveyed, showed an impressive response rate of a minimum of $55 \%$ (see Appendix 1). Likert scale statements were developed for the questionnaires and pilot tested on a small sample, in order to ensure that the statements consistently measured the themes identified at the qualitative interviews. The feedback from the pilot tests informed a review of some of the survey questionnaires. The final questionnaires for the quantitative survey consisted of three sections and an introductory cover letter explaining the purpose of the survey. Two different sets of data were collected, namely the Likert-type data and the comments made by the respondents. In support of the value chain approach more details about the import and export process, as applied to this research, are described in Appendix 2.

\section{Results}

The qualitative path involved interviews with stakeholders. The results of the qualitative interviews suggest the following challenges.

\section{Corrupt practices}

Corrupt practices in the form of bribery and extortion, were cited as a challenge affecting port efficiency by over $80 \%$ of the stakeholders in the survey, which suggests its predominant role in the value chain of activities at the ports.

\section{Nigerian Customs Services import clearing processes}

NCS were identified as an impediment to the speedy flow of cargo through the ports. The almost $100 \%$ physical examination process consists of multiple desks for processing documents, which invariably become choke points that enhance direct human contacts and opportunities for pay-offs.

\section{Transport infrastructure deficiencies}

Transport infrastructure deficiencies on the sea and land sides of the port were identified as constituting a hindrance to the efficient flow of goods through the ports.

\section{Lack of compliance with trade regulations}

Lack of compliance with trade regulations, by some shippers and customs brokers, was identified as a major factor to port inefficiency.

\section{The behavioural attitudes of the stakeholders}

The behavioural attitudes of the stakeholders also revealed the extent to which there is a lack of supply chain partnering spirit amongst them.

\section{Stakeholder-specific infrastructural and procedural challenges}

There are some stakeholder-specific infrastructural and procedural challenges, such as the lack of storage space and forklifts for positioning containers for the physical examination of cargo at the terminals and the Inland Container Depots (ICD).

The results of the qualitative survey suggest that corrupt practices, clearing processes, transport infrastructure deficiencies, lack of trade compliance and lack of supply chain partnering spirit cut across the port value chain, whilst there were some specific stakeholder infrastructural and procedural challenges.

\section{Quantitative path (questionnaire survey of stakeholders)}

Results of the quantitative surveys suggest the following challenges.

\section{Corruption}

The survey results showed that most shippers, some customs brokers, private port service providers and government agencies at the port take part in one form of corrupt practice or another.

\section{The challenges of the import processes (pre-shipment stage)}

The survey results showed that there were delays in the release of Risk Assessment Reports (RAR) ${ }^{5}$. Although there were delays in the release of RARs, Cotecna Destination Inspection Ltd. (CDIL) was by far the more efficient (in terms of quality and timeliness of output of RARs) than Global Scan Nig. Ltd. Pre-arrival and Assessment Report (PAAR) was introduced to replace RAR by NCS in 2014.

\section{Challenges of import processes (post-shipment stage)}

Of the three routes available for clearing goods (physical examination, X-ray scan and fast track), the longest, most tedious, and most convoluted predominant route is the physical examination of cargo.

\section{Export process deficiencies}

NCS inspection of export cargo at the port gates and the existence of multiple security agencies along the export chain slow down the flow of cargo through the port.

5.RAR is a document processed by the inspection agents engaged by the governmen of Nigeria (Cotecna Destination Inspection Ltd. CDIL, and Global Scan Nigeria Ltd.) without which imports cannot be cleared through the customs. 


\section{Transport infrastructure deficiencies: Land-side}

The near total absence of alternatives to road transportation, insufficiencies of the road network and a poor maintenance culture, contribute to road congestion and delays. This finding converges with problems of freight traffic at Nigerian seaports (Jaja 2011).

\section{Sea-side}

There are limitations imposed on vessel size resulting from the approach channel constraints and the Tin Can Island turning basin.

\section{Deficiencies in the Nigerian Ports Authority pilotage services}

The inadequacies in the numbers of watercrafts (tugs, pilot cutters and mooring launches), needed for pilotage operations, negatively impact on the responsiveness of the Nigerian Ports Authority (NPA) to the shipping lines. Pilotage services are not always obtained within 2 hours of the vessels' arrival at the fairway buoy, even if there were a free berthing space at the terminal.

\section{Trade fraud}

Fraudulent practices exist in the system (e.g. under-invoicing, import duty evasion, forgery of documents, sidestepping officially stipulated import channels in favour of 'grey' channels).

\section{Lack of supply chain collaboration}

There is a lack of trust and a supply chain culture amongst the port stakeholders. Policy changes at the port, with limited input from stakeholders, are difficult to predict. There is a low level of automation and digitalisation in the documentation process, resulting in repetitive submission of copies of the same document at the different stages of the chain.

\section{Service level of truckers}

Imported second-hand trucks of various ages and conditions form the backbone of the trucking industry resulting in a low level of service from the truck operators.

\section{Knowledge gaps of stakeholders}

There is, for many people in the industry, a large element of 'learning on the job' and very little occurrence of structured instruction and formalised training.

\section{Lack of port regulation}

The absence of a mechanism to trigger the transfer of containers from the APMT Apapa and TCIT to the inland container depots, upon congestion, seems to drive the behaviour of the terminals in the allocation of containers to the ICDs.

\section{Inland container depot operators' deficiencies}

The transfer of containers from the Apapa and TCIT to the ICDs takes about one week to effect.

\section{Terminal operators' deficiencies}

The service levels to exporters and truckers, with respect to loading and unloading of trucks, are quite low.

The findings of the qualitative and quantitative strands were integrated at the interpretation phase through triangulation (Plano Clark \& Creswell 2011:221-237), in order to identify and address the factors that adversely impact on the Lagos Port inefficiency.

The findings from both strands were classified under six higher-level headings with each heading defining the collective identity of the challenges listed under it. This classification makes for better integration and presentation of the findings under the themes (strategic, tactical and operational) that cut across the port value chain, rather than using a stakeholder-centred focus. The six higher-level headings, in order of strategic significance, include:

- corruption

- trade fraud

- transport infrastructure deficiencies

- the absence of a supply chain culture

- the deficiencies in services and facilities provided by state agencies and government-appointed service providers and their behaviour

- the deficiencies in the services and facilities provided by non-state stakeholders and their behaviour.

These are discussed in more detail in the following section.

\section{Reliability of the results}

The reliability controls introduced at the qualitative stage of the research (i.e. interviews of the stakeholders) included the use of multiple interview transcribers and bouncing back the themes and categories to interviewees for reconfirmation.

In order to assure the quality and reliability of the quantitative survey, a couple of steps were taken:

- A pilot testing of the instruments was conducted and the feedback was used to modify the questionnaires before the final administration to the stakeholders. Cronbach Alpha tests were conducted on the data sets and the results statistically support the reliability of the findings from the survey.

- In order to portray the mean, modal classes and the trend of the responses, the Statistical Programme for the Social Sciences (SPSS) was used to process the survey results. In all cases, the mean values of the responses were above one. More so, the standard deviations of the responses showed that there were relatively fewer variations in the opinion of the respondents to the questions. 


\section{Discussion of the results}

The objective of this study was to identify the critical factors that impact on the efficiency of the Lagos Seaport, for liner trade, with a view to offering solutions that would enable Nigeria to reduce trade logistics costs and enhance competitiveness. The following six areas summarise the findings of the qualitative and quantitative phases of the study after the results were triangulated.

\section{Corruption}

Corruption manifests itself in extortionate practices and the use of monetary inducements to obtain unfair advantage at the ports. The average stakeholder sees the others not as partners in the port value chain but as potential targets for a shakedown whenever the opportunity arises. Corruption is a problem of major strategic significance and, resulting from the reach of its tentacles into virtually all areas of port activity, is possibly the most important single factor affecting the efficient flow of containerised goods through the ports. This finding converges with the observations of Sequeira and Djankov (2009).

\section{Trade fraud}

Trade fraud, which includes non-compliance with trade regulations and guidelines by shippers, customs brokers and government agencies, is another major factor contributing to port inefficiency. Gross abuse of the 'not-valid-forforeign-exchange ${ }^{\prime 6}$ option and the sidestepping of officially designated channels for import transactions, with the involvement of government officials, exemplify trade fraud. The existence of trade fraud has always been presented by the NCS as justification for the application of a heavy regime of physical examination of goods, which invariably slows down the flow of cargo through the ports.

\section{Transport infrastructure deficits}

These cover infrastructure deficits on both the landside (roads, rail, and inland waterways) and the sea-side (approach channels and the port turning basin), and also contribute to port inefficiency. Inadequate transport infrastructure has been discussed in port literature as an impediment to port efficiency and supports this finding (Raballand et al. 2012; Refas \& Cantens 2011). It will require huge investments over a long period of time to address. This finding converges with the issues on infrastructure discussed earlier in the article.

\section{The absence of a supply chain culture}

The absence of a supply chain culture, which covers multiple documentation, frequent policy changes without stakeholder consultation, the NCS's focus on revenue generation at the expense of trade facilitation, and the poor execution of the contract of customs, inhibit the flow of goods through the ports. This deficiency was identified on three separate levels:

- internally within the NCS

- across government agencies in the port sector

- across the port community.

A lack of a supply chain culture:

- a lack of trust amongst the members of the chain

- more emphasis on the realisation of individual rather than the overall supply chain objectives

- poor coordination of the supply chain activities.

These deficiencies are a major contributory factor to the low efficiency of the ports.

\section{Deficiencies in services and facilities}

Deficiencies in services and facilities provided by state agencies (e.g. NPA, Customs, port police) and governmentappointed service providers (import/export inspection companies) can take several forms. The behaviours of the state agencies governing traffic control at the NPA gates, the inadequacies in the supply of marine services by the NPA and the absence of a port regulator, affect the efficient flow of cargo through the Lagos seaports. The deficiencies were identified under four headings:

- inadequacy of resources, knowledge, skills and diligence

- attitudinal issues

- delays arising from archaic facilities and procedures

- the absence of a port regulator.

The excessive physical examination in the execution of the customs contract delays the flow of cargo out of the port.

\section{Deficiencies in the services and facilities provided by non-state stakeholders}

Deficiencies in the services and facilities provided by nonstate stakeholders (banks, importers, exporters, truckers, brokers, terminal and ICD operators) and their behaviour, also affect the efficient flow of cargo through the ports. The deficiencies were identified under four headings:

- inadequacy of resources on the sea and land-side

- inadequacy of information technology infrastructure and services

- inadequacy in knowledge, skills and diligence

- the delays arising from archaic facilities and procedures.

The findings confirm that the issues such as the insufficiency of handling equipment, deployed by the terminal operators on the land-side, tended to adversely impact on the loading and dispatch of cargo out of the port.

The identification of the challenges opens up an opportunity to tackle and dismantle them in order to enhance liner trade activities and the connectivity of Nigeria to the network of global supply chains. Improvement in the port efficiency 
will reduce trade logistics costs and enhance Nigeria's competitiveness in the world market.

\section{Recommendations}

The recommendations are ranked from the most important to the least important. The most important are strategic in nature and exercise a heavy influence over most of the important aspects of port operations. They cut across the terminals and are pivotal in any port efficiency improvement considerations. Solutions to the problems will necessitate either the commitment of substantial levels of resources or a total overhaul and reprogramming of stakeholder attitudes and work objectives, policies, processes and procedures. The timescale for a successful resolution of these strategic issues is likely to be measured in years rather than months, and the impact of such a resolution will be major. The least important recommendations are regarded as operational and tactical in nature, and may be specific to the different stakeholders or the terminals and may not require as much effort, resources and time as those in the strategic category. The will to improve the efficiency of the port must be summoned up by the Nigerian authorities, the business community and the other stakeholders.

The recommended interventions maintain the six higherlevel groupings in order of importance.

\section{Corruption}

The combined effect of corruption, trade fraud and the absence of a supply chain culture on port operations, have resulted in lower than expected efficiencies, higher than expected transaction costs, and a poor international reputation for the Lagos seaports. The recommended measures include the establishment, within the port community, of a structure for prosecuting a war against corruption and the elimination of equipment and infrastructural shortages, which create the enabling environment for graft. In so doing the institution should be taking advantage of technological advancements to enhance the processes and procedures, and eliminate the redundancies and multiplicity of demands that characterise the existing system, to ensure visibility in transactions and accountability, which is also important.

\section{Trade fraud}

Trade fraud is unlikely to survive in the absence of official collusion in, and tolerance of, the practice. Enlisting the assistance of an internationally-based audit company, familiar with similar work elsewhere, to audit the decisions of the institutions connected with international trade transactions, is recommended. Other measures include the application of the existing laws on trade fraud, with the imposition of the specified full measure penalties on defaulting shippers and on all who collaborate or collude with the shippers.

\section{Transport infrastructure}

The improvement of municipal road traffic management in Lagos will ease congestion on port access routes, along with designating truck parks for managing pre-gate activities. Relocate export inspection away from the port gates and develop, in the long term, alternative modes of transportation to the existing road transport infrastructure. This will include rail transport and the use of inland and coastal waterways that are integrated and linked to the ports to optimise efficiencies in transportation.

\section{Supply chain culture}

The introduction and nurturing of a supply chain culture at the port should be driven by the government, and ought to include the operational modalities of government agencies operating in the ports, with a view to removing mandate conflicts, improving interagency cooperation, and reducing the burden on non-state stakeholders. Additionally, this will include the elimination of redundancies and unnecessarily heavy data demands that contribute nothing to efficiency, but rather constitute a costly drag on the smooth flow of cargo through the ports, and the encouragement of operational alliances between terminals and the ICDs and the other stakeholders.

\section{Service deficiencies provided by government and government agencies}

NCS exact the greatest influence on port operations, as its policies, procedures and practices are a major determinant of the speed at which cargo travels through the ports. As their functions increase with the transfer of the responsibilities of the inspection agents to them, NCS should vigorously pursue changes designed to improve on their effectiveness and efficiency of cargo clearance. Reference can be made to a reform package proposed by the $\mathrm{WCO}$, which contains a range of internationally agreed frameworks, conventions and instruments that provide a blueprint for modern customs administration (Truel 2010). There is the need to appoint a port regulator with the full legal backing.

\section{Service deficiencies provided by private stakeholders}

Reduce to a minimum, the delays associated with availability of handling equipment through appropriate demand reduction (especially through changes in the physical examination regime) and optimisation of resource allocation policies. Improve the robustness, capabilities and reliability of IT infrastructure and systems.

The private stakeholders should ensure uninterrupted availability of backup power sources until the national electricity grid achieves an acceptable level of availability and reliability.

\section{Conclusion}

The objective of this study was to identify the critical factors that impact on the efficiency of the Lagos seaports. The research paradigm adopted for the study was a combination of constructivism and post-positivism paradigms, which entailed the exploration of the interpretations of the various stakeholders in the port value chain. Thus, the epistemology of the research 
was predicated on the five contracts of international trade, the deployment of the value chain construct to unbundle the port operations, and the exploratory sequential mixed method research techniques at the operational level.

The study identified multiple challenges that adversely impact on the efficient flow of containerised goods through the Lagos seaports. The challenges are ranked and classified under six higher-level groupings: corruption, trade fraud, absence of a supply chain culture, transport infrastructure, deficiencies of government agencies and governmentappointed agencies, and deficiencies in services of the private sector operators at the ports.

The findings, on corruption, trade fraud, inadequate transport infrastructure, lack of supply chain culture and deficiencies of the government agencies and private organisations at the port, add to the body of knowledge on port efficiency.

\section{Acknowledgements}

The authors wish to acknowledge the contribution of Prof. Johan du Plessis whose valuable inputs contributed to the successful conclusion of the research project

\section{Competing interests}

The authors confirm that they have no financial or personal relationships which may have inappropriately influenced them in writing this article.

\section{Authors' contributions}

F.I.O. (Lagos Business School) wrote the article from the findings of his DPhil dissertation at the University of Johannesburg; J.W. (University of Johannesburg) acted as the main supervisor of the dissertation, and made revisions and additions to the article.

\section{References}

Alderton, P., 2008, Port management and operations, 3rd edn., Informa Law, Mortimer Street, London.

Barros, C.P., 2012, 'Productivity assessment of African seaports', African Developmen Review 24(1), 67-78. http://dx.doi.org/10.1111/j.1467-8268.2011.00305.x

Barros, C.P., Assaf, A. \& Ibiwoye, A., 2010, 'Bootstrapped technical efficiency of African seaports', in P. Coto-Millan et al. (eds.), Essays on port economics, contributions to economics, pp. 237, Springer-Verlag, Berlin, Heidelberg. http://dx.doi org/10.1007/978-3-7908-2425-4_15

Barros, C.P. \& Peypoch, N., 2012, 'Productivity assessment of African seaports with biased technological change', Transportation Planning and Technology 35(6) 663-675. http://dx.doi.org/10.1080/03081060.2012.710033

Bichou, K., 2009, Lloyd's practical shipping guides: Port operations, planning and logistics, Informa, London.

Bichou, K. \& Gray, R., 2005, 'A logistics and supply chain approach to seaport efficiencyAn inquiry based on action research methodology', in H. Kotzab et al. (eds.), Research methodologies in supply chain management, pp. 413-428, Physica, Heidelberg. http://dx.doi.org/10.1007/3-7908-1636-1_27

Bureau of Public Enterprises, 2006, Privatisation procedures manual, Bureau of Public Enterprise (BPE), Abuja, Nigeria.

Bureau of Public Enterprises, 2008, A case study of Nigerian Ports, Lagos, Bureau of Public Enterprise (BPE), Abuja, Nigeria.

Central Bank of Nigeria, 2002, The destination inspection of goods at the Nigerian Ports, Central Bank of Nigeria, Abuja, Nigeria.

Clark, C., 2003, Reference model of the international supply chain, BPAWG.TBG 14, UN/CEFACT. UN/CEFACT/BP044.
Creswell, J.W., 1998, 'Qualitative inquiry and research design: Choosing among five research traditions', in H. Kotzab, S. Seuring \& G. Reiner (eds.), 2005, Research methodologies in supply chain management, pp. 2-27, Physica-Verlag, Heidelberg, methodologie

Creswell, J.W., 2009, Qualitative, quantitative and mixed methods approach, Sage Publications.

David, P. \& Stewart, R., 2010, International logistics: The management of internationa trade operations, Cengage Learning, Mason, $\mathrm{OH}$.

Dean, M. \& Sebastia-Barriel, M., 2004, 'Why has world trade grown faster than world output?', Bank of England Quarterly Bulletin, Autumn, 310-320.

Djankov, S., Freund, C. \& Pham, C., 2006, 'Trading on time', Policy Research Working Paper 3909, Washington DC, The World Bank.

Economic Report on Africa, 2004, Unlocking Africa's trade potential: Trade facilitation to integrate Africa into the World Economy, Economic Commission for Africa, Addis Ababa.

Eniola, J.O., Njoku, I., Oluwatosin, A.F. \& Okoko, E., 2014, 'Performance evaluation of Nigerian ports: Pre and post concession eras', Civil and Environmental Research 6(2), viewed 10 April 2015, from http://www.iiste.org/journals/index.php/CER/ article/view/10841

Gereffi, G., 1994, 'The organisation of buyer-driven global commodity chains: How U.S. retailers shaped overseas production networks', in G. Gereffi \& M. Korzeniewicz (eds.), Commodity chains and global capitalism, pp. 95-122, Praeger, Greenwood Press Westport, CT.

Grainger, A., 2007, 'Trade facilitation: A review', Paper presented at a conference on Global supply chain security at Imperial College, London.

Grainger, A., 2011, 'Trade facilitation: A conceptual review', Journal of World Trade 45(1), 39-62.

Hummels, D., 2001, 'Time as a trade barrier', GTAP Working Papers, No. 1152, Purdue University, West Lafayette.

International Chamber of Commerce, 2010, ICC rules for the use of domestic and international trade terms, incoterms 2010 ICC publication No. 715E, ICC Publishing, USA.

International Finance Corporation/Worldbank, 2008-2013, Doing business, Co-published with the World Bank, Washinton DC, USA.

International Trade Centre, 2000, Modular learning system on international Logistics, ITC Publication, Geneva, Switzerland.

Jaja, C.Y, 2011, 'Freight traffic at Nigerian seaports: Problems and prospects', Medwell Journals: The Social Sciences 6(4), 250-258. http://dx.doi.org/10.3923/ sscience.2011.250.258

Kaplinsky, R. \& Morris, M., 2001, A handbook for value chain research, viewed 05 March 2008, from http://asiandrivers.open.ac.uk/documents/value_chain handbook_RKMM_Nov_2001.pdf

Kotzab, H., Seuring, S. \& Reiner, G. (eds.), 2005, Research methodologies in supply chain management, Physica-Verlag, Heidelberg, New York. http://dx.doi. org/10.1007/3-7908-1636-1

Nigeria Customs Service, 2007, Time release study, Nigerian Customs Service, Lagos.

Nigeria Customs Service, 2010, Simplified clearance: Guide to trade and custom agents - Procedure for self-assessment and upfront e-payment, Nigerian Customs Service, Lagos.

Park, R. \& Prabir De, 2004, 'An alternative approach to efficiency measurement of seaports', Maritime Economics and Logistics 6(1), 53-69. http://dx.doi. org/10.1057/palgrave.mel.9100094

Plano Clark, V.L. \& Creswell, J.W., 2011, Designing and conducting mixed methods research, 2nd edn., pp. 40-212, Sage Publications Inc, USA.

Porter, M., 1985, The value chain and competitive advantage. Competitive advantage: Creating and sustaining superior performance, Free Press, New York.

Raballand, G., Refas, S., Beuran, M. \& Isik, G., 2012, Why does cargo spend weeks in sub-Saharan African ports? Lessons from six countries, Directions in development Trade, World Bank. Washington, DC, USA. http://dx.doi.org/10.1596/978-0-82139499-1

Refas, S. \& Cantens, T., 2011, 'Why does cargo spend weeks in African ports? The case of Doula, Cameroun', Policy research working paper 5565, World Bank Africa Region, Transport Department, Washinton DC, USA.

Sequeira, S. \& Djankov, S., 2009, On the waterfront: An empirical study of corruption in ports, International Finance Corporation, Washington DC.

Simoes, P. \& Marques, R.C., 2010, 'Seaport performance analysis using robust nonparametric efficiency estimators', Transportation Planning and Technology 33(5), 435-451. http://dx.doi.org/10.1080/03081060.2010.502375

Staples, B.R., 2002, 'Trade facilitation: Improving the invisible infrastructure', in B. Hoekman, A. Mattoo \& P. English (eds.), Development, trade, and the WTO: A handbook, pp. 139-148, World Bank, Washington.

Steenken. D., VOß, S. \& Stahlbock, R., 2004, 'Container terminal operation and operations research: A classification and literature review', Spectrum 26, 3-49.

Truel, C., 2010, A short guide to customs risks: Classification and valuation, Gower Publishing Limited, MGP Books Group, UK.

Trugillo, L. \& Nombella, G., 1999, Privatisation and regulation of the seaport industry, vol. 2181, World Bank Publications, Washington DC. http://dx.doi. org/10.1596/1813-9450-2181

United Nations, 2010, United Nations convention on contracts for international sale of goods, UN Commission on International Trade Law, UNCTAD, Geneva. 
United Nations Centre for Trade Facilitation and Electronic Business and United Nations Conference on Trade and Development, 2002, Compendium of trade facilitation recommendations. ECE/TRADE/279, UNCTAD, Geneva.

World Bank, 2002, Ports modernisation project: Technical and financial assessment of the Nigerian Port sector, Draft evaluation report, Royal Haskoning B.V. Prepared for Federal Ministry of Transport, Abuja, Nigeria.
World Customs Organisation, 2011, Guide to measure the time required for the release of goods, WCO, Brussels.

World Trade Organisation, 2009, WTO negotiation on trade facilitation: Compilation of members' contextual proposals. Negotiating group on Trade Facilitation, TN/ TF/W/43/Rev.19, WTO, Geneva.

Appendix starts on the next page $\rightarrow$ 


\section{Appendix 1}

TABLE 1-A1: Stakeholders and selection criteria for the purposive interviews.

\begin{tabular}{llll}
\hline Stakeholders & Sample size & Minimum age of company (years) & Selection criteria \\
\hline Importers & 7 & 10 & Average imports p.a. (16 297 TEUs) \\
Exporters & 4 & 5 & Average exports p.a. (11 900 TEUs) \\
Shipping lines & 3 & 10 & Carried over $30 \%$ of the total number of TEUs to and from Lagos Ports \\
Banks & 4 & 10 & Processed over $42 \%$ of total Form Ms p.a. \\
Inland container depot operators & 3 & 5 & Handled over $50 \%$ of TEUs transferred from the terminals \\
Truckers & 7 & 15 & Transported over 9718 TEUs p.a. between the ports and the inland destinations \\
Customs brokers & 9 & 6 & Filed over 6000 import and export entries p.a. \\
\hline
\end{tabular}

TEU, Twenty-Foot Equivalent Unit.

TABLE 2-A1: Summary of questionnaire administration and response rates.

\begin{tabular}{|c|c|c|c|}
\hline Stakeholders & Number of questionnaires administered & Number of questionnaires completed and returned & Response rate (\%) \\
\hline Importers & 137 & 122 & 89 \\
\hline Exporters & 58 & 32 & 55 \\
\hline Banks & 17 & 14 & 82 \\
\hline Shipping lines & 80 & 54 & 67 \\
\hline Inland container depot operators & 16 & 11 & 68 \\
\hline Customs brokers & 130 & 102 & 75 \\
\hline Truckers & 90 & 72 & 80 \\
\hline
\end{tabular}




\section{Appendix 2}

Description of the import and export processes at the Lagos seaports.

The import process consists of eleven major activities and numerous interfaces with cycle times for the micro activities (source?). However, for clarity, the activities are designated as steps. Steps 1 and 2 of the import process are grouped together as 'cargo pre-shipment stage' Steps 3,4, and 5 are grouped as 'vessel arrival stage' whilst Steps 6, 7, 8, 9, 10 and 11 are grouped as 'cargo discharge and clearance with authorities' (i.e. post-shipment stage). Item 8, the 'cargo clearing process with the customs and the other government agencies (such as National Agency for Food and Drug Administration and Control, NAFDAC, and Standards Organisation of Nigeria, SON, and Security)' may be initiated in parallel with Step 5 . The export process consists of five major activities.

\section{The import processes}

1. Formation of sales contract between the exporter (in a foreign country) and the importer (in Nigeria).

2. Application for importation, ordering, shipment and payment for goods:

a. Call for pro-forma invoice.

b. Application for importation - completion and registration of documentation that includes the contract of marine insurance policy.

c. Contract of payment.

d. Contract of carriage.

3. Activities prior to vessel arrival at Lagos seaports.

4. Vessel's pre-arrival and clearance for entry.

5. Vessel's arrival at Fairway Buoy and berthing activities.

6. Discharge of containers and the loading of exports and empty containers.

7. Stemming containers to 'step down' and other ICDs.
8. Cargo clearing processes with the customs and other agencies:

a. Manual examination of cargo.

b. X-ray examination of cargo.

c. Fast track.

9. Cargo clearing process with the shipping lines.

10. Cargo clearing process through the terminal/ICD operator.

11. Collection of the container from the terminal/ICD operator.

\section{The export processes}

1. Formation of sales contract and sales contract agreement between the exporter (in Nigeria) and importer (in foreign country):

a. Issuance of pro-forma invoice to the overseas buyer.

b. Application for export - completion of Form NXP.

2. Contract of payment.

3. Contract of carriage.

4. Contract of insurance covering the movement of goods up to the terminal.

5. Contract of customs.

The stakeholders involved in the value chain include government agencies and government-appointed specialist firms and private organisations. The private organisations include shippers, banks, shipping lines, container terminal and off-dock/ICD operators, customs brokers and truckers. The government agencies are the NCS, Nigerian Ports Authority (NPA), Nigerian Maritime Administration and Safety Agency (NIMASA), NAFDAC, and SON, and BPE. Cotecna Destination Inspection Ltd. (CDIL), Global Scan Nigeria Ltd. (GSNL), and Cobalt International Services Ltd. are the government-appointed risk assessment and inspection agents. 